\title{
FGF/FGFR-2(IIlb) Signaling Is Essential for Inner Ear Morphogenesis
}

\author{
Ulla Pirvola, ${ }^{1,2}$ Bradley Spencer-Dene, ${ }^{3}$ Liang Xing-Qun, ${ }^{1,2}$ Päivi Kettunen, ${ }^{1}$ Irma Thesleff, ${ }^{1}$ Bernd Fritzsch, ${ }^{4}$ \\ Clive Dickson, ${ }^{3}$ and Jukka Ylikoski ${ }^{1,2}$ \\ ${ }^{1} /$ nstitute of Biotechnology and ${ }^{2}$ Department of Otorhinolaryngology, University of Helsinki, 00014 Helsinki, Finland, ${ }^{3}$ Viral \\ Carcinogenesis Laboratory, Imperial Cancer Research Fund, London, WC2A 3PX, United Kingdom, and ${ }^{4}$ Department of \\ Biomedical Sciences, Creighton University, Omaha, Nebraska 68178-0405
}

\begin{abstract}
Interactions between FGF10 and the IIIb isoform of FGFR-2 appear to be crucial for the induction and growth of several organs, particularly those that involve budding morphogenesis. We determined their expression patterns in the inner ear and analyzed the inner ear phenotype of mice specifically deleted for the IIIb isoform of FGFR-2. FGF10 and FGFR-2(IIlb) mRNAs showed distinct, largely nonoverlapping expression patterns in the undifferentiated otic epithelium. Subsequently, FGF10 mRNA became confined to the presumptive cochlear and vestibular sensory epithelia and to the neuronal precursors and neurons. FGFR-2(IIIb) mRNA was expressed in the nonsensory epithelium of the otocyst that gives rise to structures such as the endolymphatic and semicircular ducts. These data suggest that in contrast to mesenchymal-epithelial-based FGF10 signaling demonstrated for other organs, the inner ear seems to depend on
\end{abstract}

Fibroblast growth factors (FGFs 1-19) comprise a family of signaling molecules that regulate cellular proliferation, differentiation, and migration by binding to and activating members of a family of tyrosine kinase receptors (FGFRs 1-4) (for review, see Wilkie et al., 1995; Ornitz, 2000). A number of studies have implicated FGF signaling as being fundamental for pattern formation during the genesis of several tissues, suggesting that it has been repeatedly adapted for use during organogenesis. FGFs are found throughout metazoan evolution. For example, Drosophila homologs of vertebrate FGFs and FGFRs, branchless and breathless, respectively, regulate epithelial branching in the tracheal system (Klambt et al., 1992; Murphy et al., 1995; Sutherland et al., 1996). In mammals, FGF-FGFR interactions appear to regulate budding morphogenesis of the limb and the branching morphogenesis in lung formation. Recent studies have provided evidence that mesenchymederived FGF10 is the key factor that initiates and/or maintains outgrowth of FGFR-2-expressing epithelial appendages (Ohuchi et al., 1997). Compelling evidence for this suggestion has come from FGF10 null mutations and from different approaches to delete the FGFR-2 gene (Peters et al., 1994; Jackson et al., 1997; Celli et al., 1998; Min et al., 1998; Xu et al., 1998; Arman et al., 1999; Sekine et al., 1999; DeMoerlooze et al., 2000). Furthermore, recent data imply that reciprocal signaling loops between different FGFs function during morphogenesis, as exemplified in the limb bud (Ohuchi et al., 1997; for review, see Hogan, 1999).

Received Feb. 7, 2000; revised May 12, 2000; accepted June 2, 2000

This work was supported by the Academy of Finland, the Sigrid Jusélius Foundation, a Human Frontier Science Program grant (C.D.), and National Institutes of Health (B.F.). We thank Maria von Numers for expert technical assistance. We are grateful to Dr. Brigid Hogan for Fgf10 probe, Dr. Mart Saarma for BDNF, NT-3, and NF probes, Dr. David Wilkinson for FGF3 probe, Dr. Avner Yayon for FGFR-2(IIIb) probe, Dr. Peter Gruss for Pax 2 probe, and Dr. Louis Reichardt for the NT-3 null mutant mice.

Correspondence should be addressed to Ulla Pirvola, Institute of Biotechnology, University of Helsinki, P.O. Box 56, Viikinkaari 9, 00014 Helsinki, Finland. E-mail: ulla.pirvola@helsinki.fi.

Dr. Kettunen's present address: Department of Anatomy and Cell Biology, University of Bergen, N-5009 Bergen, Norway.

Copyright (C) 2000 Society for Neuroscience $0270-6474 / 00 / 206125-10 \$ 15.00 / 0$ paracrine signals that operate within the epithelium. Expression of FGF10 mRNA partly overlapped with FGF3 mRNA in the sensory regions, suggesting that they may form parallel signaling pathways within the otic epithelium. In addition, hindbrainderived FGF3 might regulate otocyst morphogenesis through FGFR-2(IIIb). Targeted deletion of FGFR-2(IIIb) resulted in severe dysgenesis of the cochleovestibular membraneous labyrinth, caused by a failure in morphogenesis at the otocyst stage. In addition to the nonsensory epithelium, sensory patches and the cochleovestibular ganglion remained at a rudimentary stage. Our findings provide genetic evidence that signaling by FGFR-2(IIlb) is critical for the morphological development of the inner ear.

Key words: FGFR-2; FGF10; FGF3; gene expression; gene disruption; inner ear development; cochleovestibular neurons
In comparison to the limb bud, the inner ear is derived from a simple ectodermal thickening, the otic placode. Although relatively little is known about the mechanisms that generate the different cell types, even less is known about how the three-dimensional morphology of the cochleovestibular labyrinth is generated (Fekete, 1996, 1999). Genetic evidence and expression data have suggested that FGF3 influences early development of the mammalian inner ear, specifically by regulating formation of the endolymphatic duct (Mansour et al., 1993; McKay et al., 1996). However, the inner ear phenotype of $F G F 3$ null mutants shows reduced penetrance and variable expressivity (Mansour et al., 1993). Therefore, a prerequisite for understanding FGF3 function in the inner ear is to characterize its receptor(s) and the possible FGF compensatory signals that could account for the partially penetrant phenotype. Of the four FGF receptors, FGFR-3 is expressed in the cochlear sensory epithelium during late embryogenesis and postnatal life (Peters et al., 1993; Pirvola et al., 1995), and a FGFR-3 null mutation leads to deafness attributable to disturbances in differentiation of the cochlear sensory epithelium (Colvin et al., 1996). Expression data have suggested that cochlear neuronderived FGF1 (Pirvola et al., 1995) and inner hair cell-derived FGF8 (Pirvola et al., 1998) may serve as ligands for FGFR-3 in the late embryonic and postnatal cochlea. FGF9 mRNA has been localized to the otic vesicle and to the later developing nonsensory epithelium and ganglion of the cochlea (Colvin et al., 1999). In addition, exogenous FGF2 has been shown to stimulate neuronal migration and differentiation in explants of the early chick inner ear (Hossain et al., 1996; Brumwell et al., 2000).

The extracellular domain of FGFRs are composed of three Ig-like domains, designated as Ig-loops-I, -II and -III. Ligand binding involves the second and third Ig-loop, although specificity is determined predominantly by Ig-loop-III. The proximal part of this loop is encoded by alternatively spliced exons for FGFRs 1-3, thereby generating two distinct receptor isoforms, designated as IIIb and IIIc isoforms, which have different ligand-binding specificities. For example, FGFR-2(IIIb) is activated by FGF1, FGF3, FGF7, and FGF10, whereas FGFR-2(IIIc) is activated by FGF1, 
FGF2, FGF4, FGF6, and FGF9 (Ornitz et al., 1996). Furthermore, the IIIb and IIIc isoforms of FGFR-2 have mainly exclusive expression patterns (Orr-Urtreger et al., 1993). A null mutation and a hypomorphic mutation of the complete FGFR-2 gene show early lethality or die in midgestation, respectively (Arman et al., 1998; $\mathrm{Xu}$ et al., 1998). More recently, mice lacking the IIIb but not the IIIc isoform of FGFR-2 have been generated by using a Cremediated excision approach. These mice are viable until birth and show disturbances in the development of multiple organs, including the inner ear (DeMoerlooze et al., 2000).

\section{MATERIALS AND METHODS}

\section{Transgenic embryos}

We analyzed the inner ear phenotype of $F G F R$-2(IIIb) null mutant mice that were generated by using Cre recombination to excise exon IIIb from the genome of targeted embryonic stem (ES) cells as described previously (DeMoerlooze et al., 2000). Genotyping of embryos was performed by PCR as described in that article.

\section{Histological analysis}

Embryos. Embryonic day 8 (E8), E9, E10, E11, E13, E14, E16, and E18 mice were collected for histological studies. Between E9 and E16, the histology of two or three mutant embryos and five control littermates was analyzed at each time point. At E8, five control embryos were studied. At E18, eight inner ears of mutant mice and six inner ears of control littermates were analyzed. The day of appearance of the vaginal plug was taken as day 0 of embryogenesis. Whole embryos and dissected E18 inner ears were fixed in $4 \%$ paraformaldehyde (PFA) in PBS, $\mathrm{pH} 7.4$, overnight at $4^{\circ} \mathrm{C}$, dehydrated, embedded in paraffin, and sectioned at $5 \mu \mathrm{m}$ in the transverse (whole embryos) and midmodiolar (dissected inner ears) plane. Sections were placed on triethoxysilane-coated slides, dried overnight at $37^{\circ} \mathrm{C}$, and stored at $4^{\circ} \mathrm{C}$. For conventional histology, sections were stained with hematoxylin and eosin.

Postnatal inner ears. Dissected inner ears of postnatal day 2 (PN2), PN7, PN14, and adult mice were fixed by perilymphatic perfusion with $4 \%$ PFA and immersed in the same fixative overnight at $4^{\circ} \mathrm{C}$. Specimens were decalcified in $0.5 \mathrm{M}$ EDTA, $\mathrm{pH} 8.0$, at $4^{\circ} \mathrm{C}$ for $2-7 \mathrm{~d}$, then dehydrated, embedded in paraffin, and sectioned as described above.

\section{In situ hybridization and probes}

The antisense and sense cRNA probes were labeled with ${ }^{35} \mathrm{~S}$-UTP by in vitro transcription. In situ hybridization was performed according to Wilkinson and Green (1990) with the modifications described earlier (Pirvola et al., 1992, 1994). Sections were counterstained with hematoxylin. The plasmids used to make the antisense and control-sense cRNA probes have been described previously: FGF10 (Bellusci et al., 1997), FGFR2(IIIb) (Orr-Urtreger et al., 1993), FGFR-2(IIIc) (Kettunen et al., 1998), FGF3 (Wilkinson et al., 1989), neurotrophin-3 (NT-3; Pirvola et al., 1992), brain-derived neurotrophic factor (BDNF; Pirvola et al., 1992), light-chain neurofilament (NF) (NF68; Pirvola et al., 1994), and Pax2 (Dressler et al., 1990). At each stage of development and during adulthood, these expressions were verified in at least four inner ears of control mice. Similarly, at least four inner ears of FGFR-2(IIIb) null mutants were used for in situ analysis at each stage of development. Sense probes did not produce any specific signal above the background level (data not shown). Bright- and dark-field illuminations were digitized by using an Olympus Provis microscope (Tokyo, Japan) and a Photometrics SenSys CCD video camera (Tucson, AZ). Figures were processed by using Image-Pro Plus 3.0 (Silver Spring, MD), Adobe Photoshop 4.0 (Adobe Systems, San Jose, CA), and Micrografx Designer 6.0 (Micrografx, Richardson, TX).

\section{Histochemistry and detection of apoptotic cells}

Immunostaining of paraffin sections with a mouse monoclonal antineurofilament antibody was performed as described previously (Pirvola et al., 1994). The avidin-biotin-peroxidase method and 3,3'diaminobenzidine were used for detection. To detect apoptotic cells, terminal deoxynucleotidyl transferase-mediated biotinylated UTP nick end labeling (TUNEL) assay was performed on paraffin sections according to manufacturer's instructions (Fluorescein In Situ Cell Death Detection Kit, Boehringer Mannheim, Mannheim, Germany). Sections were counterstained with 4',6-diamidino-2-phenylindole (DAPI) nuclear stain. Wholemount staining of NT-3 null mutant embryos for $\beta$-galactosidase activity was performed as described (Farinas et al., 1994). After staining, the embryos were prepared for paraffin sectioning as above.

\section{RESULTS}

\section{Localization of FGFR2, FGF10, and FGF3 mRNAs in the developing cochlea}

Initial stages of development

In E8 mouse embryos, the otic placode is identifiable as a thickening of the head ectoderm (Fig. $1 A$ ), which by E9 becomes invagi- nated to form a vesicle that can be seen detaching from the surface ectoderm. The E9 otic epithelium appeared homogenous in thickness, without bulges or outpocketings, indicating its undifferentiated state (Fig. 1C). Between E9 and E10, neuronal precursors started to delaminate from the ventral wall of the otic vesicle and migrate to form the cochleovestibular ganglion. In addition, the thin epithelium of the dorsal wall, the presumptive nonsensory epithelium, became distinguishable from the thicker epithelium of the ventral half of the vesicle (Fig. $1 E, G$ ). The outpocketing of the endolymphatic duct emerged from the dorsomedial wall between E10 and E11.

In the present description, "presumptive sensory epithelium" will refer to epithelial cell types that form the greater epithelial ridge of the cochlea and the sensory epithelia of vestibular organs (hair cells and supporting cells) (Fekete et al., 1998; Morsli et al., 1998). NT-3 and BDNF are used as known molecular markers for the presumptive sensory epithelium (Pirvola et al., 1992, 1994). "Neuronal compartment" will refer to migrating neuronal precursors and to the sensory neurons of the cochleovestibular ganglion.

Weak expression of FGFR-2(IIIb) mRNA was seen in the otic placode of E8 embryos (Fig. $1 A, B$ ). This expression became regionalized to the dorsal portion of the vesicle by $\mathrm{E} 9$ (Fig. $1 C, D$ ). At E10, the FGFR-2(IIIb) signal was found in the dorsal and medial walls but not in the early sensory patches of the vesicle (Fig. $1 E-H)$. The IIIc isoform-specific probe revealed low level expression of FGFR-2(IIIc) in the mesenchyme surrounding the early inner ear (data not shown).

Similar to FGFR-2(IIIb), expression of its ligand FGF10 mRNA was detected in the otic placode of E8 mice (Fig. 1I), but at higher levels than FGFR-2(IIIb) mRNA. At E9, FGF10 mRNA was prominently expressed throughout the otic vesicle but was excluded from the dorsal region expressing FGFR-2(IIIb) mRNA (Fig. 1J). Between E9 and E10, FGF10 transcripts became concentrated to a broad region in the ventral half and to a small patch in the posterodorsal wall [devoid of FGFR-2(IIIb) expression] (Fig. $1 K, L)$. By using adjacent sections, a limited degree of overlap between the FGF10 and FGFR-2(IIIb) signals was seen in the medial region of the vesicle. FGF10 mRNA was most intensely expressed in the delaminating and migrating neuronal precursors and in the early cochleovestibular ganglion, but it was not detected in the surrounding mesenchyme (Fig. $1 K, L$ ).

FGF3 mRNA, encoding another ligand for FGFR-2(IIIb), was not detected in the otic placode (Fig. $1 M$ ) but became apparent in the ventrolateral wall of the vesicle, where it colocalized with FGF10 mRNA, as revealed from adjacent sections (Fig. 1J,N). In addition, FGF3 mRNA was expressed at high levels in a large region of the hindbrain adjacent to the otic placode and early otic vesicle (Fig. 1M,N), as described previously (Wilkinson et al., 1989; McKay et al., 1996).

Together, these data provide good circumstantial evidence for a role of FGF10/FGFR-2(IIIb) signaling within the otic epithelium before and at the initiation of morphological differentiation. In addition, they provide support of a role for FGF3/FGFR-2(IIIb) in patterning of the early inner ear.

\section{Differentiating otocyst}

At E11, when morphogenetic changes of the otocyst become apparent, FGFR-2 and FGF10 mRNAs show distinct expression patterns (Fig. 2). FGFR-2(IIIb) mRNA was expressed in the thinlayered nonsensory epithelium of the dorsal half of the otocyst, in the dorsomedial outpocketing of the endolymphatic duct and in the medial wall (Fig. $2 A-D$ ). A weak signal of the IIIb isoform was also detected in the surrounding mesenchyme (Fig. $2 A-D$ ), but IIIc was the main isoform found in that compartment, although its expression level was low. The IIIc signal was also detected in the otic epithelium, but at very low levels and in a diffuse pattern (data not shown).

At E11, FGF10 mRNA was expressed in the otocyst in a pattern complementary to FGFR-2 mRNA. It was seen in the thickened patches of the presumptive sensory epithelia (Fig. $2 E, F$ ), where it 

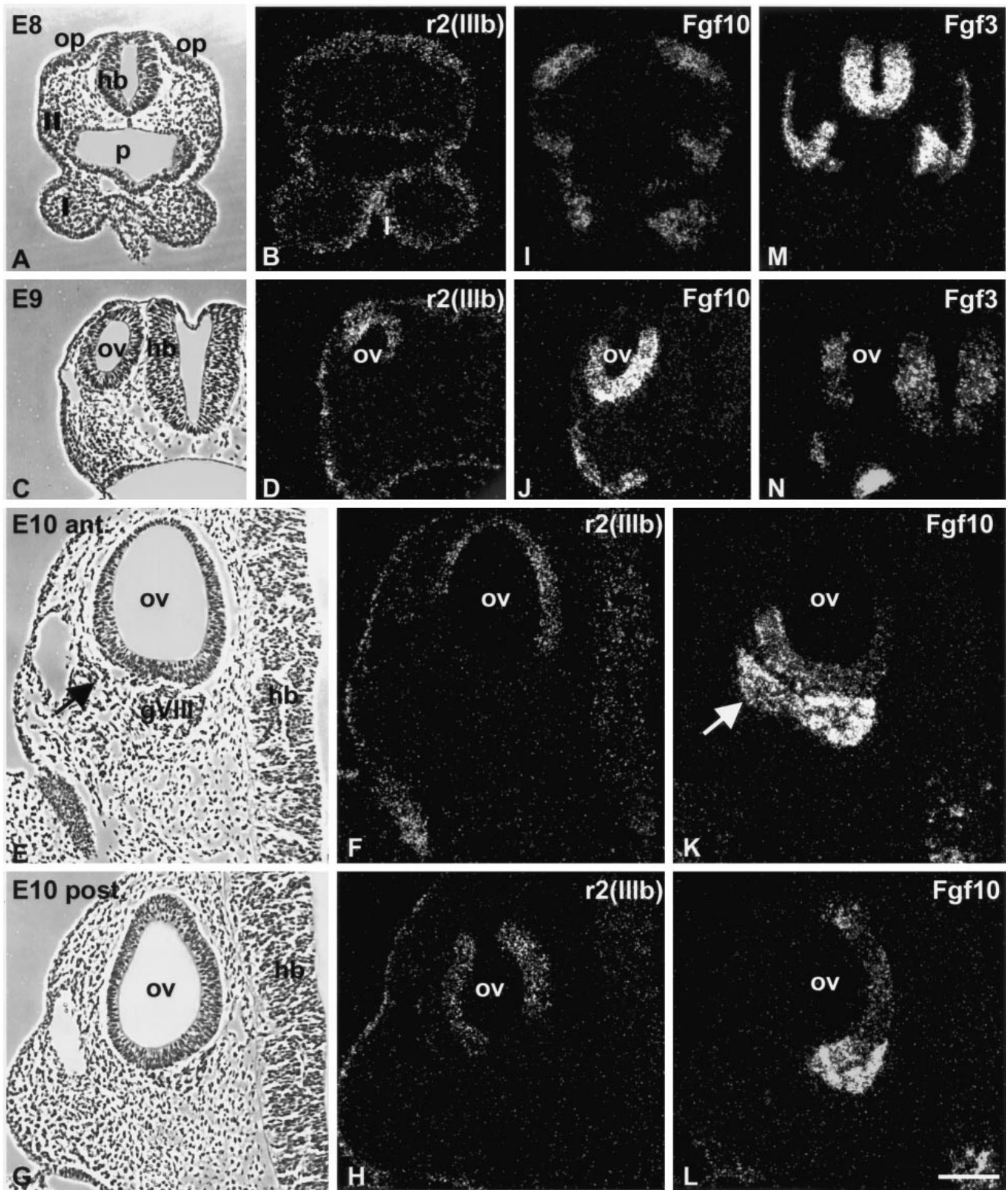

Figure 1. Expression of FGFR-2(IIIb), FGF10, and FGF3 mRNAs at the earliest stages of inner ear formation. In situ hybridizations on transverse sections photographed under phase-contrast and dark-field optics ( $A, B, I, M ; C, D, J, N ; E, F, K ; G, H, L$, adjacent sections). $A, B$, FGFR-2(IIIb) mRNA is expressed in the otic placode of E8 mouse embryos. $C$, $D$, At E9, FGFR-2(IIIb) mRNA is found in the dorsal portion of the otic vesicle that is detaching from the surface ectoderm. Anterior $(E, F)$ and posterior $(G, H)$ sections through the E10 vesicle show the FGFR-2(IIIb) signal in the dorsal and medial walls, except for the posterodorsal domain. I, FGF10 mRNA is expressed in the otic placode. $J$, At E9, strong FGF10 signal is found in the otic epithelium, except for its dorsal portion. At E10, anterior $(K)$ and posterior $(L)$ sections show the FGF10 signal in ventral and medial walls, in the migrating neuronal precursors, and in the cochleovestibular ganglion. $M$, At E8, FGF3 mRNA is prominently expressed in the hindbrain but not in the otic placode. $N$, At E9, FGF3 signal is seen in the lateral wall of the vesicle and in the region of hindbrain flanking the inner ear. ov, Otic vesicle; $g V I I I$, cochleovestibular ganglion; $h b$, hindbrain; $I$, first branchial arch; $I I$, origin of the second branchial arch; $p$, pharynx. The arrows in $E$ and $K$ mark the migrating neuronal precursors. Scale bar: $A-L, 120 \mu \mathrm{m}$.

overlapped with NT-3 (Fig. 2G) and BDNF mRNAs (data not shown), which are markers for the presumptive sensory regions (Pirvola et al., 1992, 1994). From the ventrolaterally situated patch that continued ventromedially in an anterior-to-posterior plane,
FGF10 mRNA extended into the pathway of migrating neuronal precursors and into the cochleovestibular ganglion (Fig. 2E). FGF10 mRNA was also found dorsally in a small patch of presumptive vestibular sensory epithelium (Fig. $2 F$ ). However, it was 

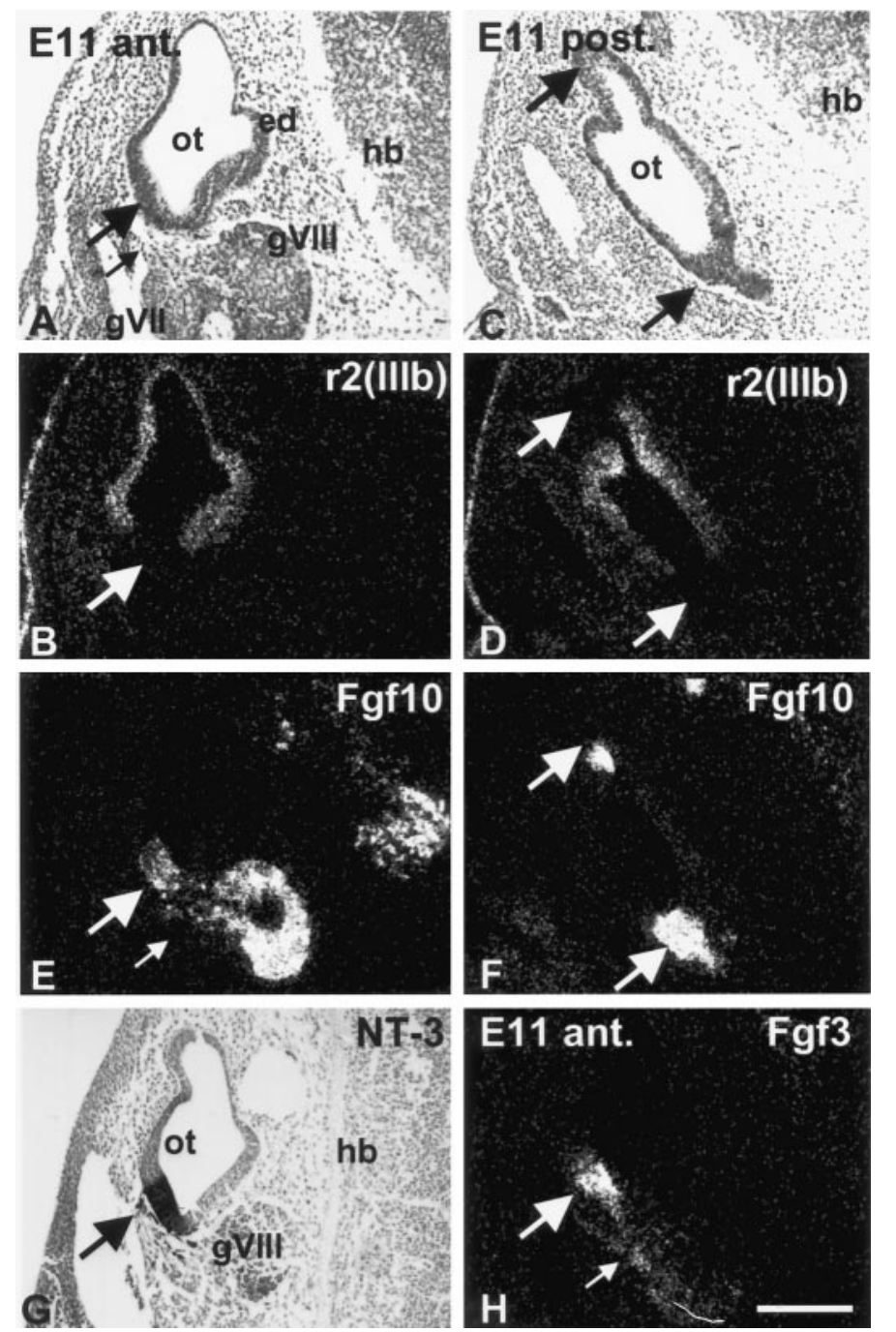

Figure 2. FGFR-2(IIIb), FGF10, FGF3, and NT-3 signals in the otocyst of E11 mouse. In situ hybridizations $(A, B, E, H ; C, D, F$, adjacent sections) on transverse sections photographed under bright- and dark-field optics, and $\beta$-galactosidase-staining $(G)$ photographed under bright-field illumination. As seen in anterior $(A, B)$ and posterior $(C, D)$ views, FGFR-2(IIIb) mRNA is expressed in large areas of the otic epithelium, except for the sensory patches (large arrows). The dorsal sensory patch is the presumptive posterior crista. Note an abundance of transcripts in the outpocketing of the endolymphatic duct. A low level of FGFR-2(IIIb) signal is seen in the surrounding mesenchyme. As seen in anterior $(E)$ and posterior $(F)$ views, FGF10 mRNA is expressed in the presumptive sensory regions (large arrows), in migrating neuronal precursors (small arrow), and in the cochleovestibular but not facial ganglion. At E11, FGF10 mRNA is also found in the hindbrain. $G$, As revealed in a NT-3 null mutant embryo, NT-3 signal is found in the ventrolateral sensory region (large arrow). $H$, FGF3 mRNA is detected in the ventrolateral sensory domain (large arrow) and in the migrating neuronal precursors (small arrow). ot, Otocyst; $e d$, endolymphatic duct; $g V I I I$, cochleovestibular ganglion; $g V I I$, facial (geniculate) ganglion; $h b$, hindbrain. Scale bar: $A-H, 160 \mu \mathrm{m}$.

not expressed in the mesenchyme surrounding the otocyst or in the nearby VIIth (Figs. $2 E, 6 A, B$ ) and IX-Xth (see Fig. $6 A, B$ ) cranial ganglia.

At E11, FGF3 mRNA was expressed in the ventrolaterally located thickened patch of the otic epithelium and weakly in the pathway of neuronal precursors (Fig. $2 H$ ), as described previously (Wilkinson et al., 1989; McKay et al., 1996). By analyzing adjacent sections, the expression pattern of FGF3 in the early inner ear was more restricted than that of FGF10 mRNA (Fig. 2E,H). The prominent FGF3 expression seen in the hindbrain of younger embryos had downregulated to low levels by E11 (Fig. $2 H$ ).

These findings show that FGF10 and FGF3 mRNAs are confined to the presumptive sensory and neuronal regions of the otocyst,
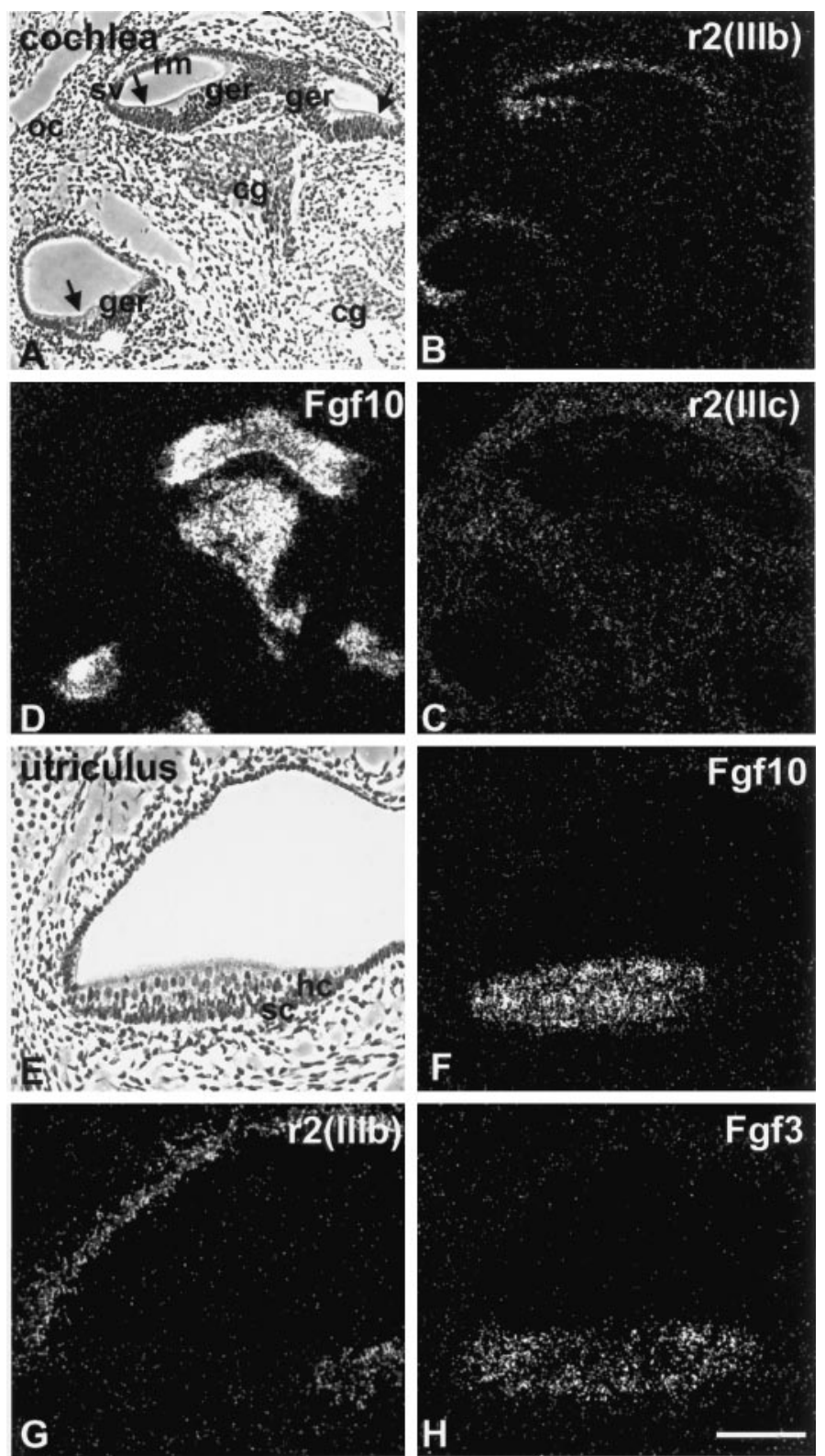

Figure 3. Expression of FGFR-2(IIIb), FGFR-2(IIIc), FGF10, and FGF3 mRNAs in the cochlea and utriculus at E16. In situ hybridizations $(A-D$; $E-H$, adjacent sections) on midmodiolar sections photographed under phase-contrast and dark-field optics. $A, B$, The IIIb isoform of FGFR-2 is found in the lateral wall of the cochlear duct and at very low levels in the surrounding mesenchyme. $C$, The IIIc isoform is expressed at low levels in the periotic mesenchyme and otic capsule. $D$, FGF10 mRNA is expressed in the greater epithelial ridge of the cochlear duct and in the sensory neurons of the cochlear ganglion. Arrows mark the differentiating hair cells. FGF10 $(E, F)$ and FGF3 $(H)$ mRNAs are expressed in the hair cells and supporting cells of utricular sensory epithelium. $H$, FGFR-2(IIIb) mRNA is found in the nonsensory epithelium of utriculus. $h c$, Hair cells; $s c$, supporting cells; ger, greater epithelial ridge; $c g$, cochlear ganglion; $r m$, Reissner's membrane; $s v$, stria vascularis; $o c$, otic capsule. Scale bar: $A-D, 120 \mu \mathrm{m} ; E-H$, $60 \mu \mathrm{m}$.

whereas the mRNA for their receptor, FGFR-2(IIIb), is expressed in the nonsensory domains. The largely nonoverlapping expression patterns suggest the presence of a paracrine signaling mechanism.

\section{Late gestational inner ear}

Expression of FGFR-2, FGF10, and FGF3 mRNAs continued in the later developing cochleovestibular labyrinth, as analyzed at E16 and E18 (Fig. 3). In the cochlear duct, FGFR-2(IIIb) transcripts were located laterally to the differentiating hair cells and to the lateral and ventral walls (Figs. $3 A, B$ ) that form the stria vascularis 
E18 control
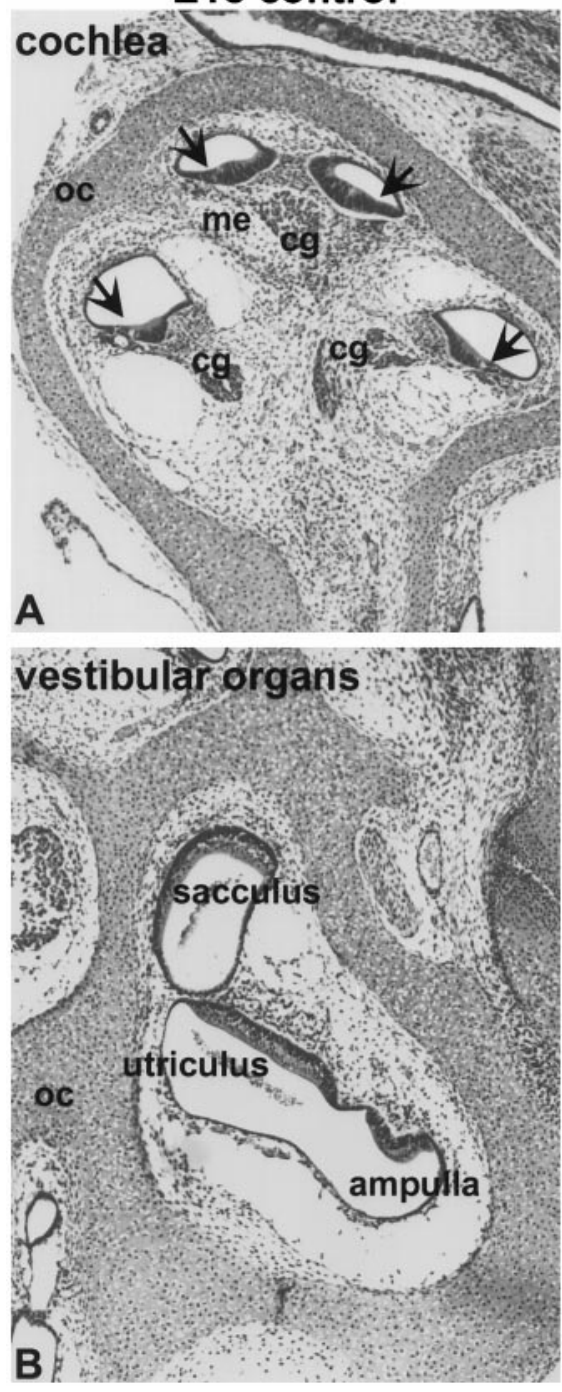

E18 Fgfr-2(IIIb) - /-

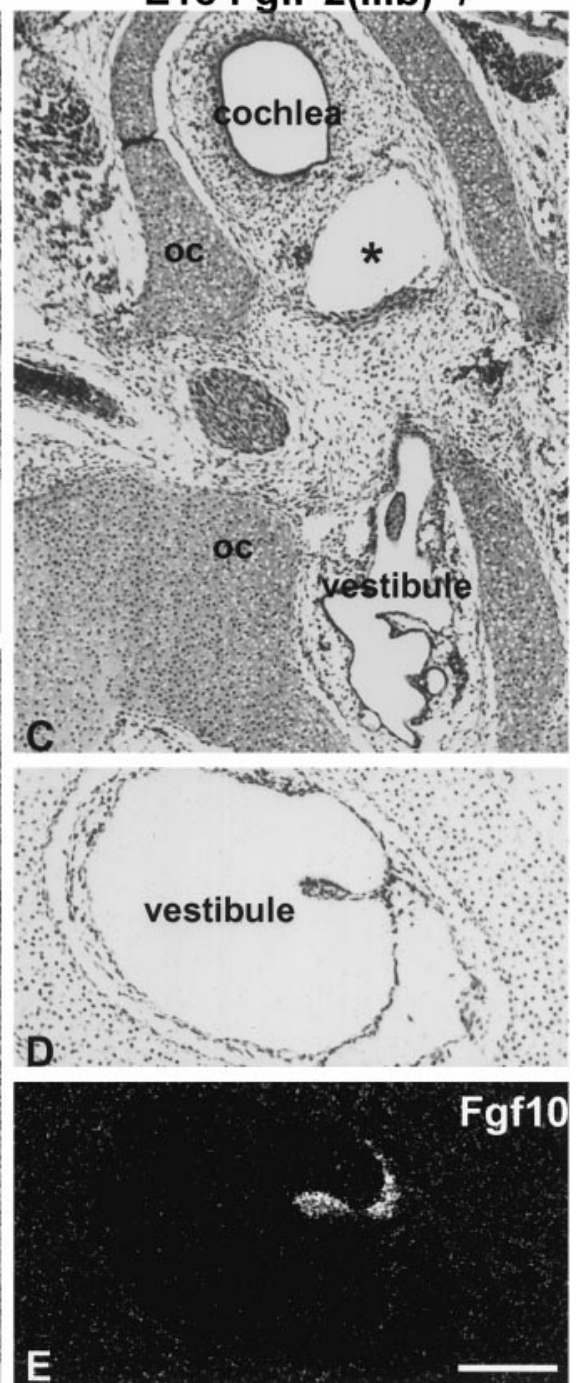

Figure 4. Targeted deletion of the IIIb isoform of FGFR-2 results in dysgenesis of the cochleovestibular membraneous labyrinth as revealed at E18. A, A midmodiolar section through the cochlea of a control mouse shows the two and one-half turns of the cochlear duct in which the differentiating sensory epithelium (arrows) and the innervating cochlear ganglion are seen. $B$, A section through the vestibular labyrinth at the level of the sensory organs of sacculus, utriculus, and ampullae of a control embryo. $C$, Both the cochlea and the vestibular labyrinth are disrupted in FGFR2(IIIb) null mutants, showing no cellular compartments of the normal morphology. Note that the otic capsule is developed in the mutant mice, although its size is reduced as compared with controls. The asterisk marks the combined scala vestibuli/tympani. $D, E$, In situ hybridization shows restricted expression of FGF10 mRNA, marking the inner ear sensory cells, in the vestibule of one mutant embryo. However, there are no signs of overt sensory organ formation that allows identification. $o c$, Otic capsule; me, mesenchyme; $c g$, cochlear ganglion. Scale bar: $A-C, 250 \mu \mathrm{m} ; D, E, 120 \mu \mathrm{m}$. and Reissner's membrane (Sher, 1971). The IIIb isoform was also expressed at very low levels in the mesenchyme. Weak and diff use expression of the IIIc isoform was detected in the otic capsule and periotic mesenchyme (Fig. $3 C$ ). In addition to the cochlear duct, FGFR-2(IIIb) signal was found in the endolymphatic and semicircular ducts and in the nonsensory epithelium of vestibular organs (Fig. 3G).

During late gestational stages, FGF10 mRNA was prominently expressed in the greater epithelial ridge of the cochlear duct (Fig. $3 D$ ), where it colocalized with NT-3 mRNA (data not shown). FGF10 mRNA was also strongly expressed in the cochlear (Fig. $3 D$ ) and vestibular sensory neurons. In addition, FGF10 mRNA was found in the sensory epithelium of all vestibular organs. The hybridization signal was seen in the differentiating hair cells and supporting cells (Figs. 3E,F). FGF3 transcripts colocalized with FGF10 mRNA in the vestibular sensory epithelia (Fig. $3 F, H$ ), but FGF10 expression was more intense. FGF3 mRNA showed restricted expression in the organ of Corti of late embryonic inner ears (data not shown), as described previously (Wilkinson et al., 1989).

\section{Postnatal inner ear}

Expression of FGFR-2 and FGF10 mRNAs persisted in the cochlea of postnatal mice (data not shown), although at lower levels than during embryogenesis. In the mature cochlea, FGFR-2(IIIb) mRNA was expressed in the inner and outer sulcus, spiral limbus, and stria vascularis. The postnatal reduction of the greater epithe- lial ridge was accompanied by a reduced expression of FGF10 mRNA to a small cell population located medially to the inner hair cells. This expression, as well as the expression in the vestibular hair cells and supporting cells, disappeared during the second postnatal week, but the inner ear neurons continued to express FGF10 mRNA in the adult.

\section{Inner ear phenotype of FGFR-2(IIIb) null mutants}

The above expression data suggested that FGF/FGFR-2 signaling could play an important role in inner ear formation. Next, we began to analyze the inner ear phenotype of mice carrying a null mutation of the IIIb isoform of FGFR-2 (DeMoerlooze et al., 2000). We were interested in the isoform-specific null mutation, because only the IIIb isoform is able to bind FGF10 and FGF3 (Mathieu et al., 1995; Ornitz et al., 1996). We were particularly interested in the receptor rather than the ligand null mutations, because of a potential functional redundancy within the FGF family in the developing inner ear (Mansour et al., 1993). Nevertheless, our unpublished results indicate an inner ear phenotype also in FGF10 null mutants.

FGFR-2 IIIb null mutant mice die at birth, because of lung agenesis (DeMoerlooze et al., 2000). Analysis at E18 showed that the cochleovestibular membraneous labyrinth was severely disrupted in the mutant mice (Fig. $4 A-E$ ); it was replaced by cystic cavities or chambers that were lined by simple epithelium. Of the eight inner ears analyzed, seven specimens did not show any evidence of sensory cell development, as verified by the lack of expression of NT-3 and FGF10 mRNAs. In one ear, the rudimen- 

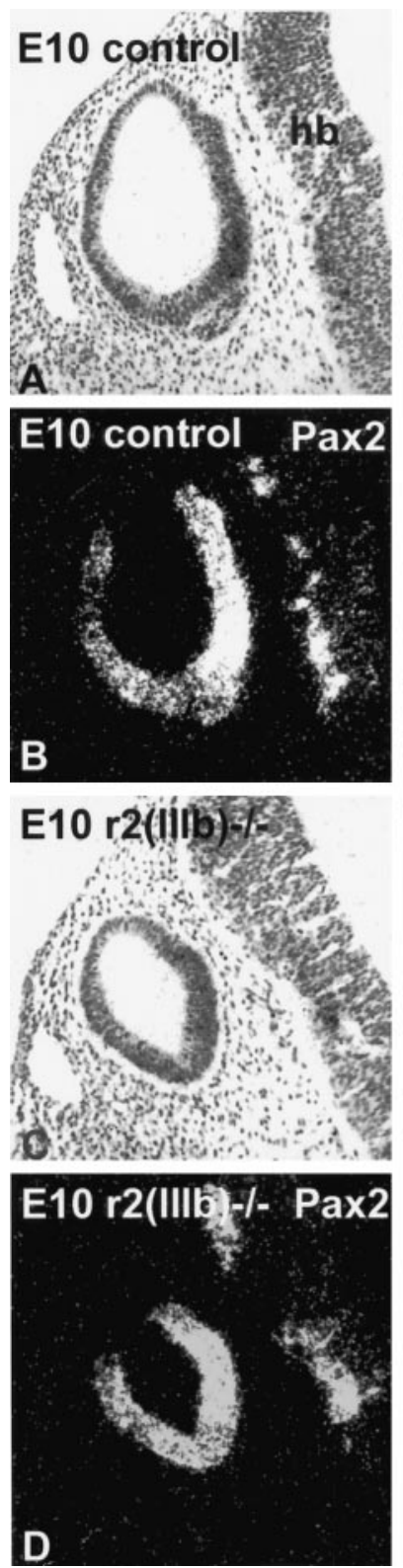
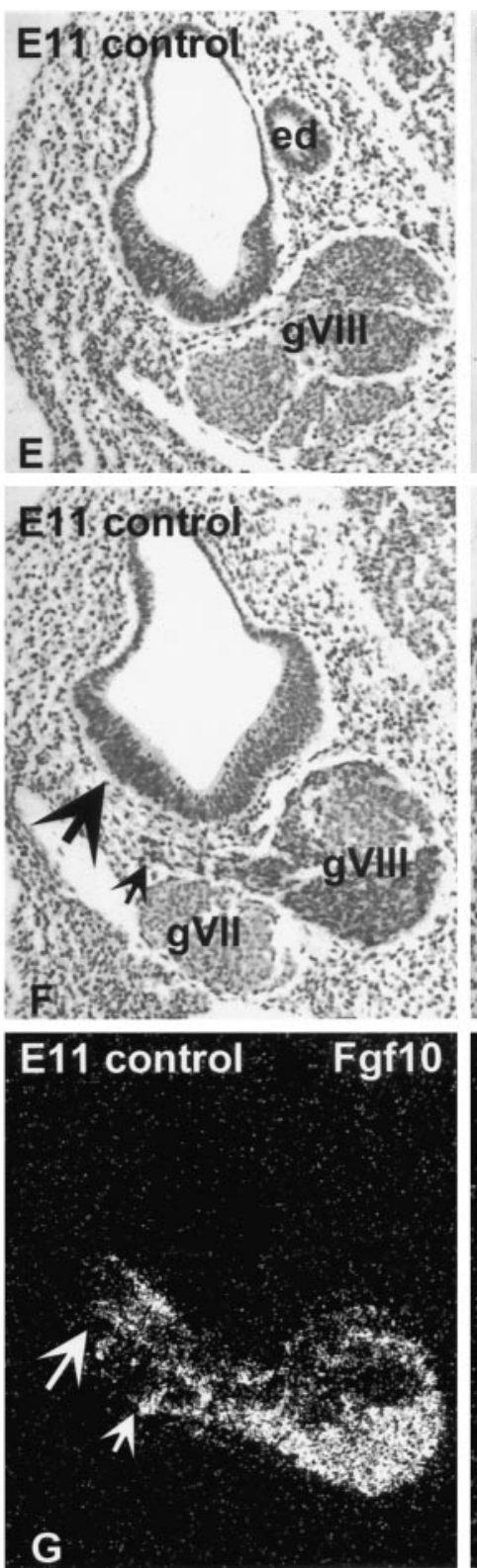
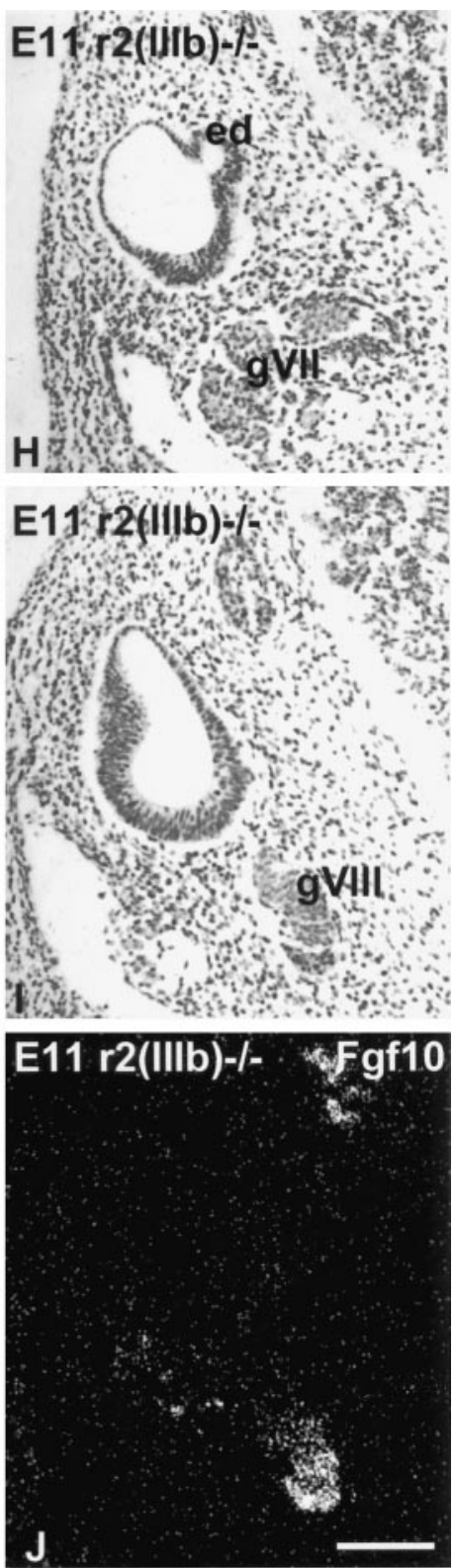

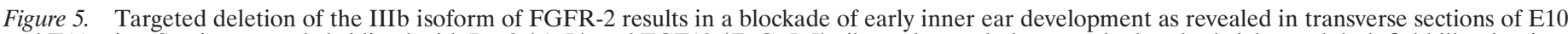

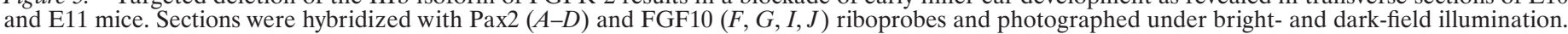

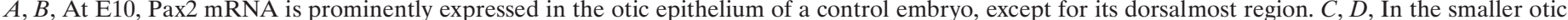

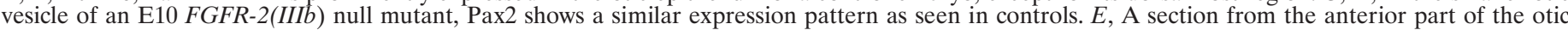

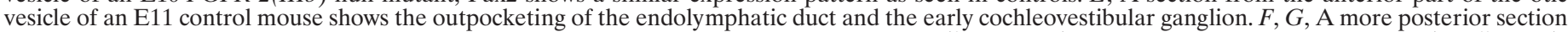

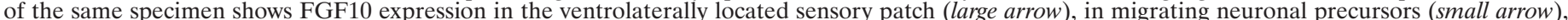

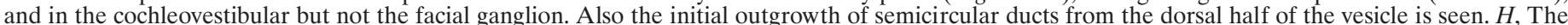

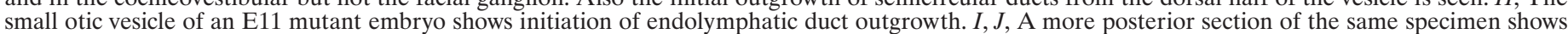

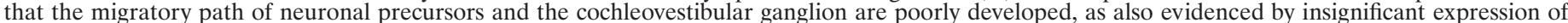

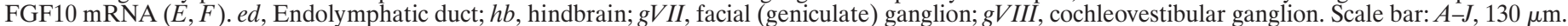

tary epithelium of both the cochlea and vestibule showed restricted expression of FGF10 mRNA, but no sign of sensory organ formation was seen (Fig. 4D,E). In mutant embryos, the otic capsule was reduced in size as compared with control littermates (Fig. 4A-C). The capsule, despite being deformed, appeared normal, also with respect to the perilymphatic system orifices (oval and round window). As anticipated, the IIIc rather than IIIb isoform of FGFR-2 predominates in the inner ear mesenchyme. In heterozygous mice, the inner ear membraneous labyrinth did not have any obvious abnormalities (data not shown).

The inner ear dysgenesis of FGFR-2(IIIb) mutant mice at birth suggested that development is inhibited at an early stage, when major morphogenetic events take place (Sher, 1971; Fritzsch et al., 1998). At E10 and E11, otic vesicles form in mutant mice, but they were significantly smaller when compared with control littermates (Fig. 5). At E10, FGF10 (present study) and Pax 2 mRNAs (Nornes et al., 1990; present study) (Fig. 5A,B) were widely expressed in the otic vesicle, except for the dorsal region. A similar pattern of gene expressions was found in the otic epithelium of the mutants (Fig. $5 C, D)$, indicating that the vesicle is at least partially subdivided into domains similar to those seen in the normal embryos. Moreover, at E10, initial delamination and migration of neuronal precursors from the ventral wall of the otic vesicle was seen in both mutant and control embryos (data not shown).

Although the otocysts of E11 mutant mice were rudimentary in size, early outgrowth of the endolymphatic and cochlear ducts could be found, similar to control littermates (Fig. 5E,H). However, there was variability in the penetrance and expressivity of the 

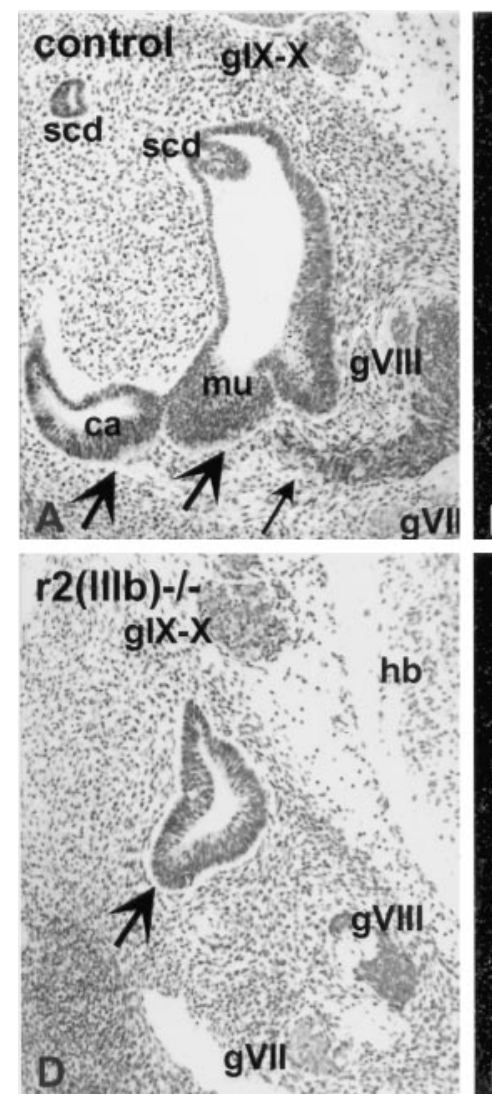
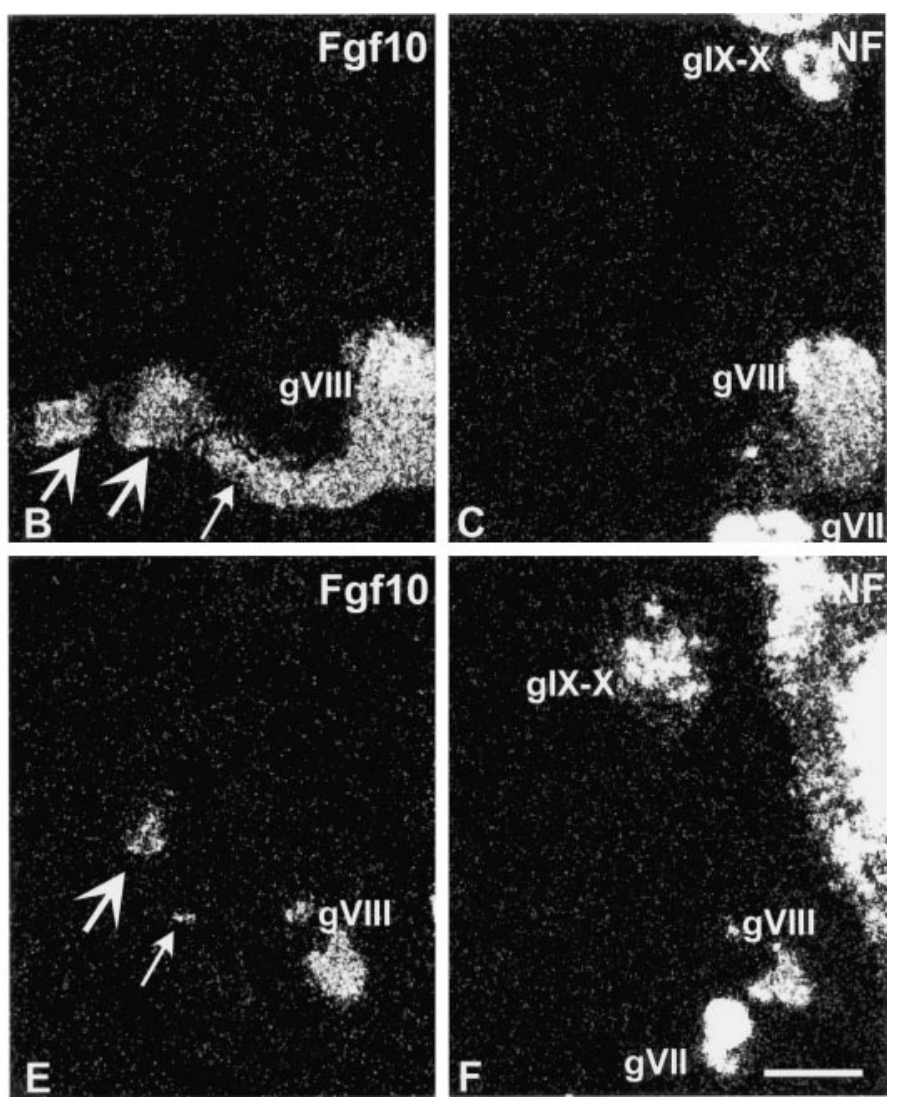

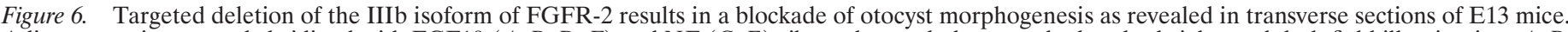

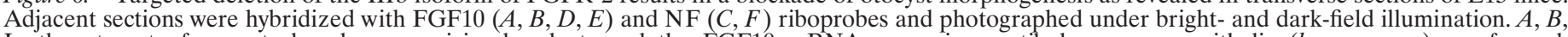

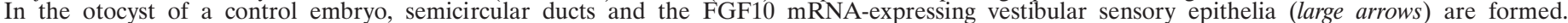

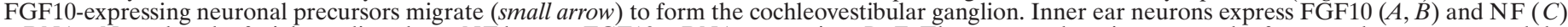

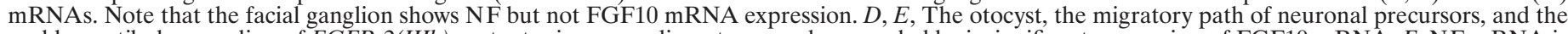

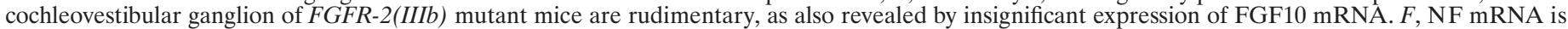

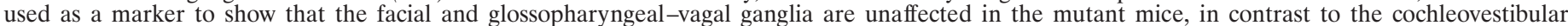

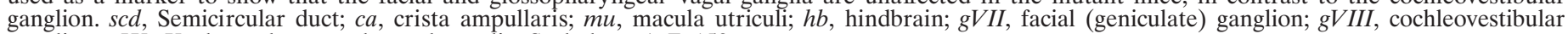
ganglion; $g I X-g X$, glossopharyngeal-vagal ganglia. Scale bar: $A-F, 150 \mu \mathrm{m}$.

endolymphatic outpocketing. Approximately $50 \%$ of otocysts of null embryos between E11 and E14 ( $n=16$ otocysts) did not show any signs of initiation of endolymphatic duct formation. In control mice, NT-3, BDNF and FGF10 (Fig. $5 F, G$ ) mRNAs were expressed in the thickened patches of the presumptive sensory epithelia. In the otocysts of mutant mice, there was only a slight thickening of the ventrally located epithelium, and it was associated with very restricted expression of the markers for the presumptive sensory epithelia (Fig. $5 I, J$ ). The vestibular sensory regions located in the dorsal part of the otocyst were even more rudimentary and did not show expression of neurotrophin or FGF10 mRNAs. Moreover, although initial delamination and migration of neuronal precursors could be seen in E10 mutant embryos, this process and the formation of the cochleovestibular ganglion were severely retarded in E11 mutants, as indicated by reduced FGF10 (Fig. $5 F, G, I, J$ ) and NF mRNAs levels used as markers for the inner ear neuronal compartment.

At E13 and E14, the otocysts of FGFR-2(IIIb) mutant embryos do not show the prominent changes in size and shape that were seen in control littermates. There was no fusion of canal plates or elongation of the semicircular or endolymphatic ducts (Fig. 6). Control embryos also formed vestibular sensory epithelia and showed distinct expression of neurotrophin and FGF10 mRNAs (Fig. 6A,B), whereas the otocysts of mutant mice showed no evidence of vestibular organ formation (Fig. $6 D, E$ ). Weak expression of FGF10 (Fig. $6 D, E$ ) and NT-3 mRNAs could be seen only in the ventral portion of the rudimentary otocyst.

At E13 and E14, the migratory pathway of neuronal precursors and the cochleovestibular ganglion were rudimentary in the FGFR-
2(IIIb) mutant mice, as verified by using FGF10 (Fig. $6 A, B, D, E$ ) and $\mathrm{NF}$ riboprobes (Fig. $6 C, F$ ). At E13, TUNEL staining revealed a large number of cochleovestibular neurons dying through apoptosis in mutant embryos, but not in controls (Fig. $7 A-D$ ). On the contrary, the ventromedial region of otocysts of control embryos at E13 showed a high apoptotic profile, in accordance with earlier data (Fekete et al., 1997), but this pattern was not seen in the rudimentary otocysts of mutant mice (Fig. $7 A-D$ ). NF immunostaining revealed that neurons of the rudimentary cochleovestibular ganglion emanated fibers toward the periphery, but in contrast to control specimens, these neurites did not penetrate the otic epithelium, where their peripheral targets, the hair cells, are located (Fig. $7 E, F)$. The nearby VIIth and IX-Xth cranial ganglia appeared normal in the mutant mice (Fig. 6A-F). The otocyst morphogenesis of heterozygous embryos appeared to proceed similarly as in wild-type littermates. Taken together, these results show that initial inner ear development occurs in FGFR-2(IIIb) mutant mice, but subsequent morphogenesis of the otocyst fails.

\section{DISCUSSION}

\section{FGF10/FGFR-2(IIIb) signaling regulates inner ear development}

The present study examines the mRNA expression patterns of FGF10 and its cognate receptor, FGFR-2(IIIb), in the inner ear. The results suggest that a largely paracrine signaling mechanism operates within the early otic epithelium and later in the cochleovestibular labyrinth. Mice deficient for FGFR-2(IIIb) develop otic vesicles from ectodermal placodes (DeMoerlooze et al., 2000; 

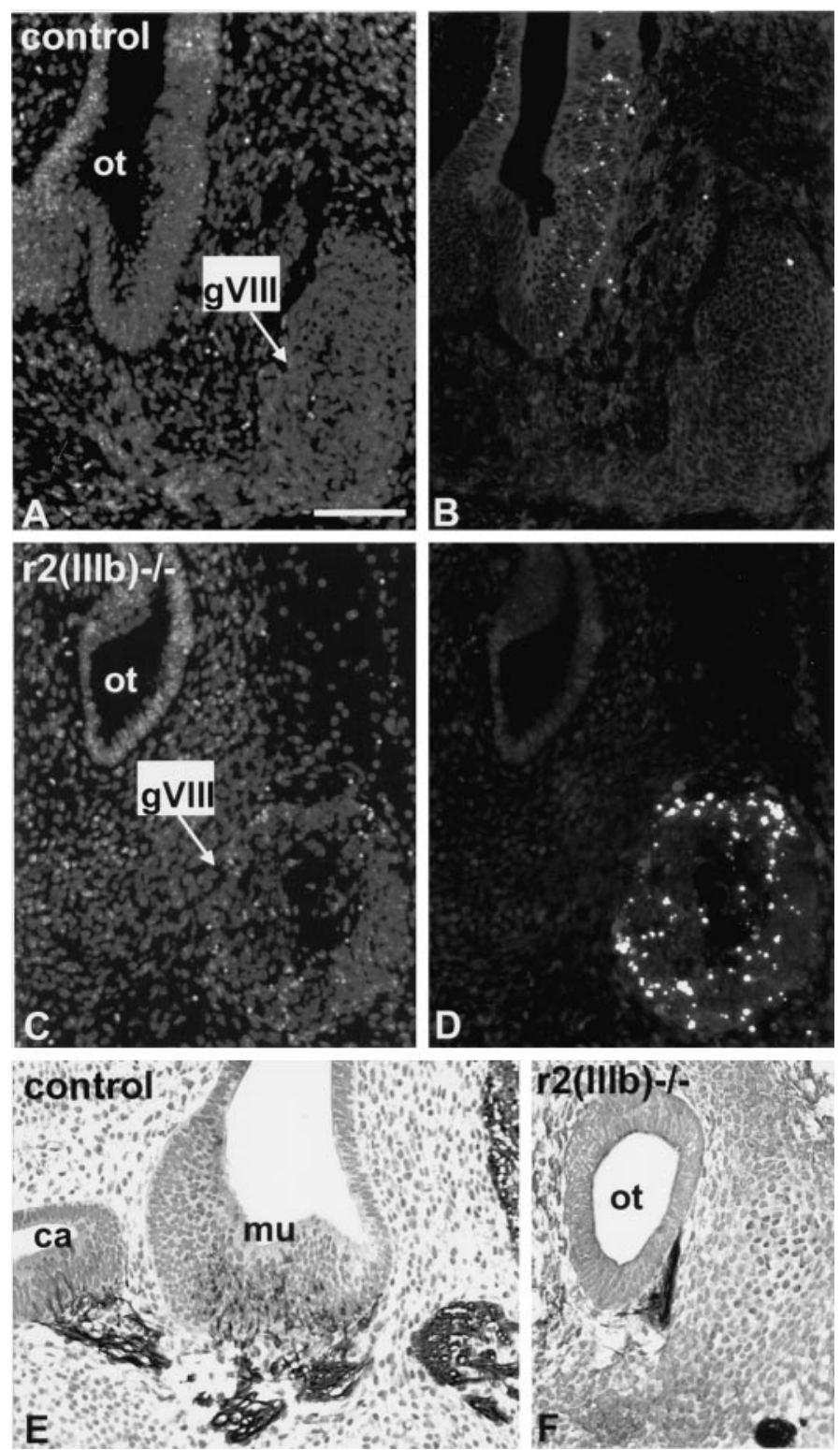

Figure 7. Targeted deletion of the IIIb isoform of FGFR-2 results in failures in the development of cochleovestibular neurons. Sections of E13 control and FGFR-2(IIIb) null mutant mice were TUNEL-stained $(B, D)$ and counterstained with DAPI $(A, C)$. Other sections were stained by neurofilament antibodies $(E, F) . A, B$, Control embryos show high numbers of apoptotic profiles in the ventromedial wall of the otocyst, but not in the cochleovestibular ganglion. $C, D$, In contrast to controls, many apoptotic neurons are seen in the cochleovestibular ganglion of a mutant mouse, and the ganglion shows signs of degeneration. Apoptotic cells are not found in the ventromedial wall of the otocyst of the mutant embryo. $E$, At E13, nerve fibers innervate the differentiating vestibular sensory epithelia of control embryos. $F$, In mutant mice, a low number of nerve fibers have grown toward the otocyst, but they do not penetrate the epithelium. Differentiation of the vestibular sensory epithelia is not evident in the mutant embryo. ot, Otocyst; $g$ VIII, cochleovestibular ganglion; $m u$, macula utriculi; $c a$, crista ampullaris. Scale bar: $A-D, 60 \mu \mathrm{m} ; E, F, 80 \mu \mathrm{m}$.

present study), indicating that FGFR-2(IIIb) signaling is not critical for the earliest stages of inner ear formation. This finding is in accord with earlier data on mice with a homozygous hypomorphic allele (Xu et al., 1998). The latter null mutants, however, die at the early otic vesicle stage, at the time when its morphogenesis is started. With an isoform-specific targeted deletion, we now provide evidence that FGFR-2(IIIb) is essential for morphogenesis of the otic vesicle. Our observations of an inner ear rudiment at birth are in agreement with the findings of another study that used a lossof-function approach using a secreted dominant-negative form of FGFR-2(IIIb) (Celli et al., 1998).

\section{Dynamic expression patterns of FGF10 and FGFR-2(IIIb) mRNAs}

Initially, FGF10 mRNA was widely expressed in the undifferentiated otic epithelium but became subsequently restricted to the presumptive cochlear and vestibular sensory patches (a broad ventral region and a small posterodorsal patch). In addition, strong expression of FGF10 mRNA was found in the otic epitheliumderived neuronal precursors and in the neurons of the cochleovestibular ganglion. It has been shown that neuronal precursors detach and migrate from the ventral portion of the otic vesicle to form the cochleovestibular ganglion (Altman and Bayer, 1982; Carney and Silver, 1983). The expression pattern of FGF10 mRNA and its colocalization with neurotrophin mRNAs in the ventral patch suggest that the inner ear neurons and part of the sensory epithelium have a common origin in this epithelial domain. Within the cranial ganglia, expression of FGF10 mRNA was found uniquely in the cochlear and vestibular ganglia and not in the nearby VIIth and IX-Xth ganglia. Whether FGF10 expression relates to the unique colocalization of neurotrophin receptors, $\operatorname{trk} B$ and $t r k C$, in the inner ear sensory neurons (Pirvola et al., 1994; Fritzsch et al., 1999) remains to be tested in FGF10 null mutant mice.

A previous study has shown expression of FGFR-2(IIIb) mRNA in the epithelium and FGFR-2(IIIc) mRNA in the mesenchyme of the midgestational inner ear (Orr-Urtreger et al., 1993). Here we show that this differential expression pattern of the two isoforms is maintained throughout inner ear development. In addition, we define the specific epithelial domains for the expression of FGFR2(IIIb) mRNA. It was expressed in the undifferentiated otic epithelium, specifically in the dorsal portion of the early otic vesicle, a region suggested to give rise to the nonsensory epithelium ( $\mathrm{Li}$ et al., 1978). Accordingly, this mRNA was subsequently found in the nonsensory epithelium of the cochlea and vestibular organs and in the nonsensory outpocketings such as the endolymphatic duct and semicircular canals. Importantly, FGFR-2(IIIb) null mice are defective for these nonsensory structures, showing an early blockade of their formation. Incorporating these results together with the findings of largely nonoverlapping expression patterns for FGFR2(IIIb) and FGF10 mRNAs, we suggest that this signaling regulates specification of the nonsensory epithelium of the inner ear. Because FGFs are thought to act as short-range diffusible morphogens (Hogan, 1999), FGF10/FGFR2(IIIb) signaling might happen along the boundaries of the expression domains (or within their limited overlap), and these boundary regions would then define the origin of the nonsensory outpocketings. In some mutant mice, initial development of the endolymphatic duct was observed, but this outgrowth did not proceed beyond the earliest stages. Therefore, in addition to the initiation of morphogenesis, FGF10, secreted from the differentiating sensory and neurogenic regions, might regulate further development of the FGFR-2(IIIb)-expressing nonsensory epithelium.

Altogether, on the basis of the budding morphogenesis theme, it appears that correlations can be made between the developing inner ear and organs such as the limb bud and lung. In all cases, the outgrowth of appendages seems to be regulated by FGF10/FGFR2(IIIb) signaling (Bellusci et al., 1997; Xu et al., 1998; DeMoerlooze et al., 2000; Kettunen et al., 2000). However, in contrast to some other organs in which this signaling appears to involve a mesenchymal to epithelial interaction (for review, see Hogan, 1999), in the inner ear it appears to operate primarily within the epithelium.

The present histological and molecular analyses show that the sensory epithelia and the cochleovestibular ganglion, as well as the nonsensory structures, are rudimentary in FGFR-2(IIIb) null mutant mice. Failure to develop inner ear neurons appears to result from disturbances at the level of neuronal precursors. However, in contrast to the inner ear nonsensory epithelium, the sensory and neuronal regions were largely devoid of FGFR-2(IIIb) expression. Therefore, the failure of sensory structures to develop might be caused by disturbances at the initial stages of specification of different epithelial domains, the null mutation inhibiting the estab- 
lishment of boundaries between dorsal and ventral cell types. However, partial axis fixation was observed in the vesicles of FGFR-2(IIIb) mutants, based on regionalization of FGF10 and Pax 2 expressions and initial delamination of neuronal precursors from the ventral wall. Alternatively, reciprocal interactions between the sensory/neuronal and nonsensory domains or even more intricate signaling loops between the epithelium and the surrounding mesenchyme might occur and could explain the loss of the sensory components found in FGFR-2(IIIb) null mice. It has become increasingly evident that FGF signaling operates on the basis of reciprocal paracrine interactions (for review, see Hogan, 1999). In accordance with our suggestion, grafting experiments have pointed to communication between different domains of the otic epithelium (Swanson et al., 1990). However, although the present study suggests the candidate molecules acting from the sensory compartments to the nonsensory epithelium, the converse remains obscure.

FGFR-2(IIIb) null mutants fail to form the cochleovestibular ganglion at the level of neuronal precursors. However, a small neuronal population was formed, and these neurons extended fibers to the periphery but did not innervate the otic epithelium. High numbers of apoptotic neurons were seen within the early cochleovestibular ganglion of mutant mice. This distinct apoptosis is likely to result from a failure of the sensory patches to differentiate and to promote survival of the innervating neurons by producing neurotrophic factors (Pirvola et al., 1994; Fritzsch et al., 1999).

Because of the severe effects of the targeted deletion of FGFR$2(I I I b)$ on early inner ear development, these mutant mice did not shed light on the possible role of FGF10/FGFR-2(IIIb) signaling during later developmental events. In late gestational inner ears, FGF10 mRNA continued to be expressed in the sensory compartments and FGFR-2(IIIb) mRNA in the nonsensory epithelial structures. Hence, it is possible that FGF10, secreted from the greater epithelial ridge, may impact on the development of the FGFR2(IIIb)-expressing Reissner's membrane and stria vascularis. However, on the basis of our unpublished results, FGF10 might signal through a receptor other than FGFR-2(IIIb) within the late embryonic cochlear duct, specifically within the sensory compartment. This signaling would be in line with the short-range mode of action of FGFs in general (Hogan, 1999). Because expression of FGF10 mRNA was maintained in the vestibular hair cells and supporting cells during the first 2 postnatal weeks, FGF10 might act on the FGFR-2(IIIb)-expressing nonsensory epithelial structures of the vestibular labyrinth even after birth.

\section{FGF3 and FGF10 may regulate inner ear development through FGFR-2(IIIb)}

Both FGF3 and FGF10 bind and activate the IIIb isoform of FGFR-2 (Mathieu et al., 1995; Ornitz et al., 1996). Although FGF3 mRNA is localized to the otic epithelium, more attention has been paid to the putative role of hindbrain-derived FGF3 on the early inner ear, based on the expression of FGF3 mRNA in the rhombomeres adjacent to the otic vesicle (Wilkinson et al., 1989; McKay et al., 1996). Hindbrain-derived FGF3 has been suggested to regulate patterning of the inner ear, particularly endolymphatic duct formation, based on the phenotype of FGF3 null mutants (Mansour et al., 1993). This suggestion is attractive, especially because we now show that FGFR-2(IIIb) mRNA is expressed in the dorsomedial wall of the vesicle that is flanking the hindbrain and later in the outpocketing of the endolymphatic duct. However, not excluding the suggestion of a hindbrain-derived FGF3 signal, FGF3/FGFR-2(IIIb) signaling within the otic epithelium is also possible. By analysis throughout development, we found that FGF3 mRNA is expressed in the ventrolateral domain of the otic vesicle at the same stage when it is seen in the hindbrain, raising the possibility that FGF3 derived from both sources concomitantly acts on the otic epithelium. Similar to FGF10, FGF3 expression continued in the otocyst and later in the sensory epithelia of the cochlea and vestibular organs. FGF3 and FGF10 mRNAs showed partly overlapping expression patterns, but FGF10 mRNA was more intensely and more widely expressed. Hence, local production of both FGF3 and FGF10 could act on the FGFR-2(IIIb)expressing nonsensory epithelium. It remains to be shown whether FGF3 signals derived from the otic wall and hindbrain have the same site(s) of action within the broad FGFR-2(IIIb) expression domain, taking into account that FGFs in general act as short-range signals.

In addition to the possibility that hindbrain-derived FGF3 might have an impact on the FGFR-2(IIIb)-expressing otic epithelium, the present expression data suggest a potential redundancy for the otocyst-derived FGF3 and FGF10 signals. Support for this comes from the variable inner ear phenotype reported for FGF3 null mutant mice (Mansour et al., 1993), which share similarities with the FGFR-2(IIIb) mutant mice reported here. For example, in both $F G F 3$ and FGFR-2(IIIb) mutants, formation of the nonsensory epithelial outpocketings and the cochleovestibular ganglion were disrupted. In FGFR-2(IIIb) null mice and in the severely affected $F G F 3$ null mice, slight initial differentiation of these structures could be found. Also in line with the FGFR-2(IIIb) mutants, the otic capsule did not show major defects in FGF3 mutants, consistent with the predominance of IIIc isoform of FGFR-2 in the mesenchymal compartments of the inner ear (Orr-Urtreger et al., 1993; present study). However, although the phenotype of inner ears of FGF10 null mutants (Min et al., 1998; Sekine et al., 1999) has not been reported, our unpublished results suggest a milder phenotype in FGF10 than in FGF3 null mutants. These preliminary results argue for an important role of hindbrain-derived FGF3 in otocyst morphogenesis. In conclusion, the present study provides evidence that FGF3 and FGF10 function as paracrine regulators of gross morphological patterning of the inner ear by activating the IIIb isoform of FGFR-2. Our results indicate that disruption of this ligand-receptor interaction leads to dysgenesis of the inner ear membraneous labyrinth.

\section{REFERENCES}

Altman J, Bayer S (1982) Development of the cranial nerve ganglia and related nuclei. Adv Anat Embryol Cell Biol 74:1-90.

Arman E, Haffner-Krausz R, Chen Y, Heath JK, Lonai P (1998) Targeted disruption of fibroblast growth factor (FGF) receptor 2 suggests a role for FGF signaling in pregastrulation mammalian development. Proc Natl Acad Sci USA 95:5082-5087.

Arman E, Haffner-Krausz R, Gorivodsky M, Lonai P (1999) Fgfr2 is required for limb outgrowth and lung-branching morphogenesis. Proc Natl Acad Sci USA 12:11895-11899.

Bellusci S, Grindley J, Emoto H, Itoh N, Hogan BLM (1997) Fibroblast growth factor 10 (FGF10) and branching morphogenesis in the embryonic mouse lung. Development 124:4867-4878.

Brumwell CL, Hossain WA, Morest DK, Bernd P (2000) Role for basic fibroblast growth factor (FGF-2) in tyrosine kinase (TrkB) expression in the early development and innervation of the auditory receptor: in vitro and in situ studies. Exp Neurol 162:121-145.

Carney PR, Silver J (1983) Studies on cell migration and axon guidance in the developing distal auditory system of the mouse. J Comp Neurol 215:359-369.

Celli G, LaRochelle WJ, Mackem S, Sharp R, Merlino G (1998) Soluble dominant-negative receptor uncovers essential roles for fibroblast growth factors in multi-organ induction and patterning. EMBO J 17:1642-1655.

Colvin JS, Bohne BA, Harding GW, McEwen DG, Ornitz DM (1996) Skeletal overgrowth and deafness in mice lacking fibroblast growth factor receptor 3. Nat Genet 12:390-397.

Colvin JS, Feldman B, Nadeau JH, Goldfarb M, Ornitz DM (1999) Genomic organization and embryonic expression of the mouse fibroblast growth factor 9 gene. Dev Dyn 216:72-88.

DeMoerlooze L, Spencer-Dene B, Revest JM, Hajihosseini M, Rosewell I, Dickson C (2000) An important role for the IIIb isoform of fibroblast growth factor receptor-2 (FGFR-2) in mesenchymal-epithelial signalling during mouse organogenesis. Development 127:483-492.

Dressler GR, Deutsch U, Chowdhury K, Nornes HO, Gruss P (1990) Pax2, a new murine paired-box-containing gene and its expression in the developing excretory system. Development 109:787-795.

Farinas I, Jones KR, Backus C, Wang XY, Reichardt LF (1994) Severe sensory and sympathetic deficits in mice lacking neurotrophin-3. Nature 369:658-661.

Fekete DM (1996) Cell fate specification in the inner ear. Curr Opin Neurobiol 6:533-541.

Fekete DM (1999) Development of the vertebrate ear: insights from knockouts and mutants. Trends Neurosci 22:263-269. 
Fekete DM, Homburger SA, Waring MT, Riedl AE, Garcia LF (1997) Involvement of programmed cell death in morphogenesis of the vertebrate inner ear. Development 124:2451-2461.

Fekete DM, Muthukumar S, Karagogeos D (1998) Hair cells and supporting cells share a common progenitor in the avian inner ear. J Neurosci 18:7811-7821.

Fritzsch B, Barald K, Lomax M (1998) Early embryology of the vertebrate ear. In: Development of the auditory system, Springer handbook of auditory research (Rubel EW, Popper AN, Fay RR, eds), pp 80-145. Springer: New York.

Fritzsch B, Pirvola U, Ylikoski J (1999) Making and breaking the innervation of the ear: neurotrophic support during ear development and its clinical implications. Cell Tissue Res 295:369-382.

Hogan BLM (1999) Morphogenesis. Cell 96:225-233.

Hossain WA, Zhou X, Rutledge A, Baier C, Morest DK (1996) Basic fibroblast growth factor affects neuronal migration and differentiation in normotypic cell cultures from the cochleovestibular ganglion of the chick embryo. Exp Neurol 138:121-143.

Jackson D, Bresnick J, Rosewell I, Crafton T, Poulsom R, Stamp G, Dickson C (1997) Fibroblast growth factor receptor signalling has a role in lobuloalveolar development of the mammary gland. J Cell Sci 11:1261-1268.

Kettunen P, Karavanova I, Thesleff I (1998) Responsiveness of developing dental tissues to fibroblast growth factors: expression of splicing alternatives of FGFR1, -2, -3, and of FGFR4; and stimulation of cell proliferation by FGF-2, -4, -8, and -9. Dev Gen 22:374-385.

Kettunen P, Laurikkala J, Itäranta P, Vainio S, Itoh N, Thesleff I (2000) Associations of FGF3 and FGF10 with signaling networks regulating tooth morphogenesis. Dev Dyn, in press.

Klambt C, Glazer L, Shilo BZ (1992) Breathless, a Drosophila homolog, is essential for migration of tracheal and specific midline glial cells. Genes Dev 6:1668-1678.

Li CW, Van De Water T, Ruben RJ (1978) The fate mapping of the eleventh and twelfth day mouse otocyst: an in vitro study of the sites of origin of the inner ear sensory structures. J Morphol 157:249-267.

Mansour SL, Goddard JM, Capecchi MR (1993) Mice homozygous for a targeted disruption of the proto-oncogene int-2 have developmental defects in the tail and inner ear. Development 117:13-28.

Mathieu M, Chatelain E, Ornitz D, Bresnick J, Mason I, Kiefer P, Dickson C (1995) Receptor binding and mitogenic properties of mouse fibroblast growth factor 3. Modulation of response by heparin. J Biol Chem 270:24197-24203

McKay IJ, Lewis J, Lumsden A (1996) The role of FGF-3 in early inner ear development: an analysis in normal and kreisler mutant mice. Dev Biol 174:370-378.

Min H, Danilenko DM, Scully SA, Bolon B, Ring BD, Tarpley JE, DeRose M, Simonet WS (1998) FGF10 is required for both limb and lung development and exhibits striking functional similarity to Drosophila Branchless. Genes Dev 12:3156-3161.

Morsli H, Choo D, Ryan A, Johnson R, Wu DK (1998) Development of the mouse inner ear and orgin of its sensory organs. J Neurosci 18:33273335.

Murphy AM, Lee T, Andrews CM, Shilo BZ, Montell DJ (1995) The breathless FGF receptor homolog, a downstream target of Drosophila $\mathrm{C} / \mathrm{EBP}$ in the developmental control of cell migration. Development 121:2255-2263.

Nornes HO, Dressler GR, Knapik EW, Deutsch U, Gruss P (1990) Spatially and temporally restricted expression of Pax2 during murine neurogenesis. Development 109:797-809.
Ohuchi H, Nakagawa T, Yamamoto A, Araga A, Ohata T, Ishimaru Y, Yoshioka H, Kuwana T, Nohno T, Yamasaki M, Itoh N, Noji S (1997) The mesenchymal factor, FGF10, initiates and maintains the outgrowth of the limb bud through interaction with FGF8, an apical ectodermal factor. Development 124:2235-2244.

Ornitz DM (2000) FGFs, heparan sulfate and FGFRs complex interactions essential for development. Bioassays 22:108-112.

Ornitz DM, Xu J, Colvin JS, McEwen DG, MacArthur CA, Coulier F, Gao G, Goldfarb M (1996) Receptor specificity of the fibroblast growth factor family. J Biol Chem 271:15292-15297.

Orr-Urtreger A, Bedford MT, Burakova T, Arman E, Zimmer Y, Yayon A, Givol D, Lonai P (1993) Developmental localization of the splicing alternatives of fibroblast growth factor receptor-2 (FGFR2). Dev Biol 158:475-486.

Peters K, Ornitz D, Werner S, Williams L (1993) Unique expression pattern of the FGF receptor 3 gene during mouse organogenesis. Dev Biol 155:423-430.

Peters K, Werner S, Liao X, Wert S, Whitsett J, Williams L (1994) Targeted expression of a dominant negative FGF receptor blocks branching morphogenesis and epithelial differentiation in the mouse lung. EMBO J 13:3296-3301.

Pirvola U, Ylikoski J, Palgi J, Lehtonen E, Arumäe U, Saarma M (1992) Brain-derived neurotrophic factor and neurotrophin-3 mRNAs in the peripheral target fields of developing inner ear ganglia. Proc Natl Acad Sci USA 89:9915-9919.

Pirvola U, Arumäe U, Moshnyakov M, Palgi J, Saarma M, Ylikoski J (1994) Coordinated expression and function of neurotrophins and their receptors in the rat inner ear during target innervation. Hear Res 75:131-144.

Pirvola U, Cao Y, Oellig C, Suoqiang Z, Pettersson RF, Ylikoski J (1995) The site of action of neuronal acidic fibroblast growth factor is the organ of Corti of the rat cochlea. Proc Natl Acad Sci USA 92:9269-9273.

Pirvola U, Xing-Qun L, Virkkala J, Fuxe J, Pettersson R, Ylikoski J (1998) FGF-8 and its high affinity receptors are expressed in the mammalian and chick cochlea. Association for Research on Otorhinolaryngology, MidWinter Meeting, February 15- 19. Abstract 665.

Sekine K, Ohuchi H, Fujiwara M, Yamasaki M, Yoshizawa T, Sato T, Yagishita N, Matsui D, Koga Y, Itoh N, Kato S (1999) FGF10 is essential for limb and lung formation. Nat Genet 21:138-141.

Sher AE (1971) The embryonic and postnatal development of the inner ear of the mouse. Acta Otolaryngol 285[Suppl]:1-77.

Sutherland D, Samakovlis C, Krasnow MA (1996) branchless encodes a Drosophila FGF homolog that controls tracheal cell migration and the pattern of branching. Cell 87:1091-1101.

Swanson GJ, Howard M, Lewis J (1990) Epithelial autonomy in the development of the inner ear of a bird embryo. Dev Biol 137:243-257.

Wilkie AO, Morriss-Kay GM, Jones EY, Heath JK (1995) Functions of fibroblast growth factors and their receptors. Curr Biol 5:500-507.

Wilkinson DG, Green J (1990) In situ hybridization and the threedimensional construction of serial sections. In: Postimplantation mammalian embryos (Copp AJ, Cockroft DL, eds), pp 155-171. Oxford: IRL.

Wilkinson DG, Bhatt S, McMahon AP (1989) Expression pattern of the FGF-related proto-oncogene int-2 suggests multiple roles in fetal development. Development 105:131-136.

Xu X, Weinstein M, Li C, Naski M, Cohen RI, Ornitz DM, Leder P, Deng C (1998) Fibroblast growth factor receptor 2 (FGFR2)-mediated reciprocal regulation loop between FGF8 and FGF10 is essential for limb induction. Development 125:753-765. 